\title{
The Mixture Of Yogurt And Strawberry Juice To Repair Blood Lipid Profile
}

\author{
Rince Alfia Fadri", Rilma Novita ${ }^{\#}$,Fadil Oenzil ${ }^{*}$, and Kesuma Sayuti ${ }^{\#}$ \\ \# Program Study of Food Technology, Polytechnic of Agricultural, University of Andalas, 26271 Payakumbuh, West Sumatera, Indonesia \\ E-mail rince.alfia@yahoo.co.id
}

*Faculty of Medicine, University of Andalas

${ }^{\#}$ Faculty of Agricultural Technology, University of Andalas, Padang 25163, West Sumatera, Indonesia

\begin{abstract}
There are so many ways to do in reducing cholesterol concentration in blood. Yogurt and strawberry juice have ability to repair blood lipid profile at hypercholesterolemia. Research and lactobacillus development potention as the cholesterol killing probiotic that to be mixed with strawberry juice is necessary to do to support community health. The purpose of this reasearch was measuring the mixture of yogurt and strawberry juice effectiveness to repair blood lipid profile. The design of this research that to be used was experimental by pretest and posted randomized control design progam. The sample of this research was thirty white mice (Rattus Norvegicus). Cholesterol Total, HDL and LDL to be analyzed by WI-M-KK2 BLK-SB methode (Clinical Chemstry Auto Analyzer) using tool Selectra E Auto Analyzer. The data was analyzed by Anova test, continued by LSD test using computer program - The result after giving mixture of yogurt and strawberry juice with the dosage $2 \mathrm{ml}$ and $3 \mathrm{ml}$ per day could obviously reduce $\mathrm{LDL}$ Level $(p<0,05)$, Cholesterol Total $(p<0,05)$ and to increase HDL Level $(p>0,05)$. The differentiation in dosis giving showed unmeaning reduction result $(p>0,05)$. Conclusion, the mixture of yogurt and strawberry juice could repair blood lipid profile, where it's proved to reduce drastically choleterol Total Level, LDL in 30 days.
\end{abstract}

Keywords - Yogurt; Strawberry Juice; Lipid Profile; Hypercholesterolemia.

\section{INTRODUCTION}

Some media mentioned that Minang Ethnic occupy the highest position in hypertension and cholesterol because of its eat pattern. According to Health Limapuluh Kota district office (Dinas Kesehatan Kabupaten Limapuluh Kota) (2005) hypercholesterolemia number was $14.4 \%$ for women and $12,4 \%$ for men. This incident rose to $16,2 \%$ for women and $14 \%$ for men. The prevalence of community hypercholesterolemia reached 200-248 mg/dl. Young generation sufferer in the age of 25-34 years reached 9,3\%. Women was being the most suffered in this case which's $14,5 \%$ or almost twice as men group. A person has high risk affected by coronary heart disease (PJK) if cholesterol total concentration more than $240 \mathrm{mg} / \mathrm{dl}$, the LDL (Low Density Lipoprotein) plasma cholesterol more than $160 \mathrm{mg} / \mathrm{dl}$ and HDL cholesterol (High Density Lipoprotein) less than 35 $\mathrm{mg} / \mathrm{dl}[1]$.

Many ways that can be used to reduce cholesterol concentration in the blood. Some studies indicated the Lactobacillus that is transferred from the media of laboratory (in vitro) into the body (in vivo properties) has the potential to reduce cholesterol in the blood [2]. The Mixture of yogurt and strawberry juice have ability to repair blood lipid profile [3]. Yogurt is one of probiotics dairy products drinks which are processed through the process of fermentation by adding good cultures organism, one of them is lactic acid bacteria. Strawberry (Fragaria chiloensis) is a fruit herb plant that has two hundred tiny seeds per one fruit. Several phytochemical compounds that was found in strawberry fruit are antosianin, acid elagiat, katekin, kuaerferin and kaemferol. One of the antosianin function is as antioxidants in the body to avoid atherosclerosis. Antosianin works to hamper aterogenesis process by oxidize the LDL.

Research and development of Lactobacillus potential as probiotic cholesterol reductant mixed with strawberry juice need to be done to support community health. The purpose of this research was measuring the mixture of yogurt and strawberry juice effectiveness to repair blood lipid profile. 


\section{METHODS}

Research design to be used was experimental by pretest and posted randomized control design. This design was used to measure treatment effect in the experimental group by comparing that group with control group. This research sample was thirty white mice (Rattus Norvegicus). The sample divided to be six groups, one negative control group, one positive control group and four treatment groups. Sample size in this research was five mice for each group. Giving mixture of yogurt and strawberry juice was done per oral by gavage for about thirty days. Selectra E Autoanalyzer was the tool used to examine cholesterol total, Cholesterol LDL, and Cholesterol HDL in the blood. Sonde needle was used to inject yogurt and strawberry juice through experimental mice with the dosage $2 \mathrm{ml}$ and $3 \mathrm{ml}$ per day.

The materials used were standard feed at the rate of 20 gr/tail/day, hypercholesterolemia feed as addition feed to increase mice's cholesterol level exogenously in order to reach hypercholesterolemia condition. Feeds with the cholesterol composition $1,5 \%$ goat fat, cooking oil $6 \%$ and standard feed till $100 \%$. All the materials were stirred up until well mixed and transformed to be pellet form like standard feed [4]. Hypercholesterolemia condition to the mice could be reached by giving addition food in high cholesterol level for thirty days.

Cholesterol total, HDL and LDL analysed using WI-MKK 2 BLK-SB method (Clinical Chemistry Autonalyzer) and the tool used was calibrated Selecrta E Autoanalyzer at UPTD, West Sumatera Province Health laboratory. To measure the effect of giving yogurt mixture and strawberry juice to the blood lipid profile was done One Way Anova examine using statistic 8 software and to make differentiate for each treatment was done Least Significant Difference (LSD) on trusted degree $95 \%(\mathrm{p}<0,05)$.

\section{RESULT AND DISCUSSION}

Hypercholesterolemia condition reached by giving hypercholesterolemic feed for thiry days. Cholesterol level increasing may caused by three things. First, diet contained much cholesterol and fat so that body has no ability to control it. Second, Cholesterol excretion to the colon trough by little gall acid. Third, in case when the cholesterol production in the liver in great quantities [5].

Mice's cholesterol level increasing by the time yogurt and strawberry juice giving caused by hypercholesterolemic feed. It's encourage over cholesterol forming that influential to cholesterol increasing in the blood. Goat fat that was got by frizzling was oxidated fat product. Oxidation fat product got into the body and to be in the blood lipoprotein as oxidated cholesterol. Low Density Lipopreotein (LDL) brought oxidated cholesterol in form of modified-LDL [5]. Increasing cholesterol in the research probably caused by oxidated cholesterol increasing that contained in the LDL.

High cholesterol total could be reduced by yogurt and strawberry juice giving for thirty days. Mixed yogurt and strawberry juice giving drastically imroved blood lipid profile of white mice. Average cholesterol level increasing after hypercholesterolemic feed giving and reduction cholesterol total level after yogurt giving, strawberry juice also yogurt mixed and strawberry juice is seen on Picture 1.
In the other side mixed yogurt and strawberry juice giving, cholesterol LDL level $(\mathrm{mg} / \mathrm{dl})$ on the average before and after yogurt giving to the white mice treatment, strawberry juice also yogurt and strawberry juice for each treatment group had real reduction compared with positive control. Cholesterol LDL reduction is showed on the picture 2 .

Yogurt giving, strawberry juice also mixed yogurt and strawberry juice gave the same effect to cholesterol LDL reduction where for each group treatment was not real different. This proved that by just yogurt giving, just strawberry juice or both of them could reduce drastically cholesterol LDL of white mice.

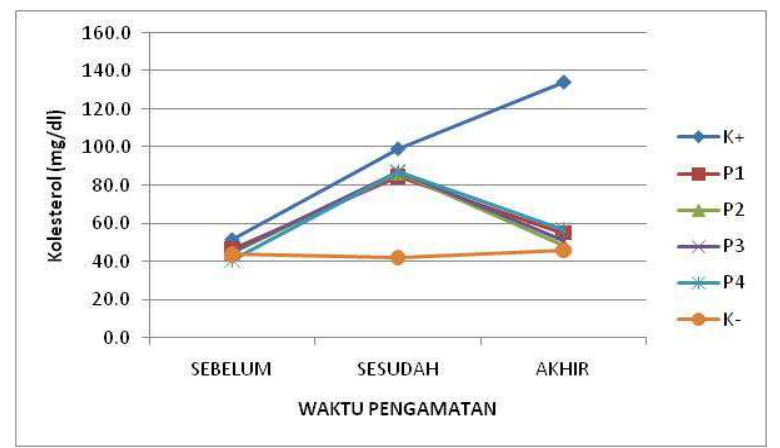

Picture 1. The Grafic of Cholesterol Total Level Average (mg/dl) of white mice

Cholesterol total level before hypercholesterolemic feed giving

Cholesterol total level after hypercholesterolemic feed giving and before yogurt and strawberry juice treatment.

Cholesterol total level of white mice after yogurt and strawberry juice treatment.

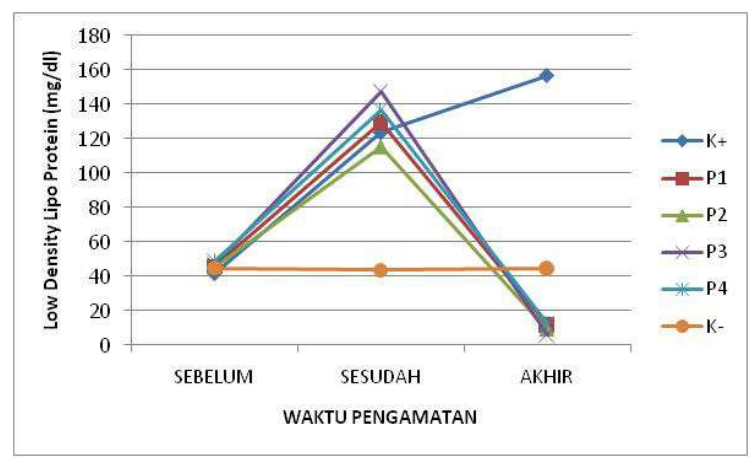

Picture 2. The Grafic of Cholesterol LDL Level Average (mg/dl) of white mice

Cholesterol LDL level before hypercholesterolemic feed giving

Cholesterol LDL level after hypercholesterolemic feed giving and before yogurt and strawberry juice treatment.

Cholesterol LDL level of white mice after yogurt and strawberry juice treatment.

Cholesterol LDL level after yogurt and strawberry juice giving to the white mice is showed on the picture 3 . White mice's cholesterol LDL level on the end treatment a little bit increased where the increasing for reach group showed not real different. If to be compared with negative control group showed real different, and so positive control group.

The other mechanism may happened is there's cholesterol assimilition activity by Lactobacillus casei strain Shirota bactery. According to reference [5], research result after fermentation milk giving contained Lactobacillus casei shirota gives effect to real reducing on cholesterol total and cholesterol LDL. This blood cholesterol level reducing 
caused by BAL ability that's L.casei in cholesterol. Assimilation. L. Casei will take or absorb the cholesterol and next the cholesterol will collect together to be one on bacteria cellular membrane, so that the bacteria is more endure to the lisys. The consequence of diet cholesterol absorption from digestion system, cholesterol level in the blood will also to reduce.

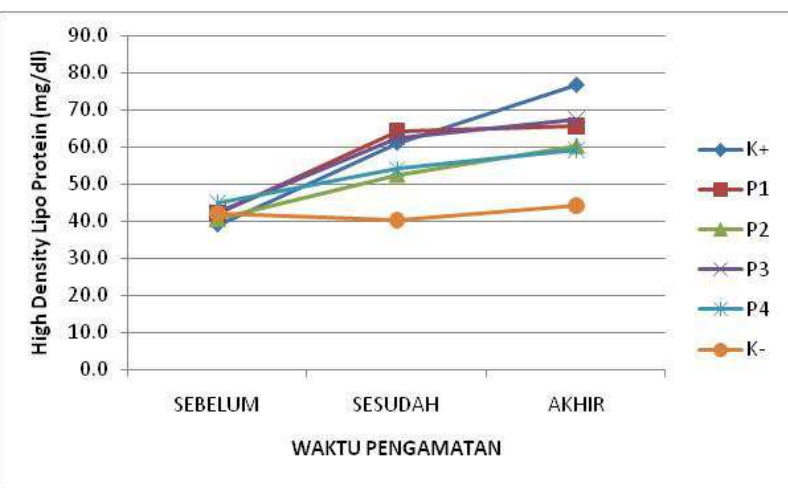

Picture 3. The Grafic of Cholesterol HDL Level Average (mg/dl) of white mice

Cholesterol HDL level before hypercholesterolemic feed giving

Cholesterol HDL level after hypercholesterolemic feed giving and before yogurt and strawberry juice treatment.

Cholesterol HDL level of white mice after yogurt and strawberry juice treatment.

In the strawberry juice contained anthocyanin that has function as the antioxidant in the body so that it can prevent ateroklerosis occurred, the blood vessels clogging disease. Anthocyanin works to prevent aterogenesis process by oxidizing LDL. Antosianin also protects endotel cell integrity that covering the vessels walls so no damage occured. Endotel cell damage is the beginning of ateroklerosis forming so it needs to be avoided. In the other hand, in the strawberry juice contains high vitamin $\mathrm{c}$ to increase HDL level that will sweep cholesterol LDL out, to increase throwed cholesterol speed in gall acid, prevent LDL oxydation so it helps preventing plaque formed on the vessels that may cause heart vessels to be clogged. Next it has function as pulmer so that increasing feces banishment where this case also to reduce reabsorption gall acid and its convertion to be cholesterol (Kurowska, 2002).

So based on this research to get maximal healthy advantages from foods, no wrong if applying synergy foods concept in daily menu. Optimal healthy advantages will be not reached if only stocked-still to curtained nutrition supplement consumption. Various healthy food combination is a good solution to get healthy life. By running food synergy concept will be got many advantages like optimal nutrition food absorption, hungry controlling and body weight also to reduce cholesterol level and to maintain cholesterol level in normal condition.

Beside clinical aspect to reduce cholesterol level, many things that we can see from this research just like functional foods combination that will produce positive synergy or foods synergy in the development of foods and nutrition's. So far, we just always be stunned to one kind of food component advantage. Like suggestion to consume vitamin $\mathrm{c}$ to keep body stay healthy or much zinc consumption to prevent anaemia or to eat one kind of antioxidant to avoid free radical. But, by food pattern changing around with new paradigm to move to functional foods, perception mistakes that to consume supplement like certain nutrition hopely can be protected from diseases attack can be muffled. From the research result can be proved that a certain nutrition work ability needs interaction with others nutrition in order that give maximal advantages, except that certain kinds of food combination like yogurt and strawberry juice can to increase the advantages of that food by consume it togetherly.

\section{CONCLUSIONS}

The Mixture of yogurt and strawberry juice can repair blood lipid profile, where it is proved to reduce drastically cholesterol total level, LDL in thirty days. Continuation research is needed about antioxidant activities in strawberry and to examine any compounds that dominantly most in reducing cholesterol level.

\section{REFERENCES}

[1] R. D. Hatma., Nutrient Intake Relation to Lipid Profiles in Diverse Etnic Population and Their, Disertation Post Graduate Program University of Indonesia, 2001

[2] A. Yuniastuti., "Effect of Fermented Milk Lactobacillus casei strain Shirota on Serum Lipid Changes in the levels of Fraction Rat Hiperkolesterolemi." Thesis. Disertation Post Graduate Program University of Diponegoro. Semarang. 2003

[3] R. A. Fadri., " The effect of strawberry extract to lowering cholesterol" Tesis. Disertation Post Graduate Program University of Andalas, 2010

[4] Kelompok Kerja Ilmiah (KKI) Phyto Medica., " Guidelines Testing and Development Fitofarmak, Foundation for the Development of Natural Products Drug. Jakarta. 1993

[5] F. Baraas, Prevent Heart Attack By Pressing Cholesterol. Cetakan Pertama. Gramedia. Jakarta. 1993 